\title{
Alexander V. Kutchin, Lyudmila N. Shishkina, and Larissa \\ I. Weisfeld (Eds): Chemistry and Technology of Plant Substances-Chemical and Biochemical Aspects
}

\author{
John Edmondson ${ }^{1}$
}

(C) Springer-Verlag GmbH Germany 2017

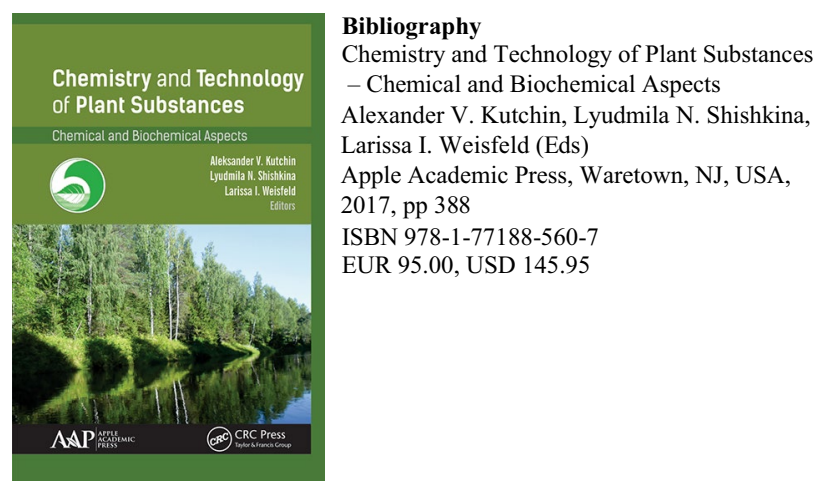

This multi-author work summarises components of plant origin and their biological activity. The first part covers several classes of compound, ranging from monoterpenoid derivatives, terpene acid derivatives, conversion of lignocellulose materials to fatty acids, and ethanol, and also has a chapter on ammonia immobilisation by peat in agriculture. Though the authors, several of whom contributed to each chapter, have Russian names the quality of the English-language text cannot be faulted.
The second part of the book also covers a disparate range of topics, from bio-indicators of oil-contaminated soils to essential (plant) oils of the Astrakhan region. Each chapter is generously referenced, the Russian language articles being cited in Roman transliteration. If there is an overall theme, it seems to be focussed on the processing of plant raw materials, though there are several references to analytical methods. The principal publisher, Apple Academic Press, is based in Canada and the USA, but the book is distributed in the UK by Taylor \& Francis on behalf of their subsidiary CRC Press. The book is sturdily case-bound and has an index, though some errors have crept into the spelling of scientific names such as "Amarantus" (for Amaranthus) and "Lophantus anisatum" (for Lophanthus anisatus). One is clearly the result of an out-of-control spellchecker, "Magnolia obovate" (for obovata).

In conclusion, this book seems to exemplify the trend towards online publishing of collective works that can be monetized through readers' downloads. In this case, the whole book is available as a downloadable PDF, whereas the journal model would allow any single article to be accessed.
John Edmondson

chromatographia@springer.com

1 Royal Botanic Gardens, Richmond, UK 